\title{
REFLEXÕES SOBRE ÉTICA, ESTADO BRASILEIRO E EDUCAÇÃO
}

\section{Dante Henrique Moura}

Professor do CEFET-RN, Engenheiro eletricista, Doutor em Educação, Coordenador do Núcleo de Pesquisa em Educação - NUPED/CEFET-RN. dante@cefetrn.br

Recebido em março de 2006 e aceito em maio de 2006

\begin{abstract}
RESUMO
Neste trabalho, discutimos a questão ética nas relações entre o estado brasileiro e os cidadãos, a partir de uma análise do papel do Estado, especialmente na esfera educacional. Para isso nos valemos de uma revisão bibliográfica e de nossa própria experiência e conhecimento teórico-prático como profissional da educação. Inicialmente, fizemos um resgate do sentido da ética e, posteriormente, realizamos análise à qual nos propusemos considerando como referencial o valor igualdade entre os indivíduos no que se refere ao acesso à educação. $\mathrm{O}$ estudo nos permitiu concluir que a relação entre o estado brasileiro e seus cidadãos carece de ética, uma vez que a igualdade não é alcançada sequer do ponto de vista formal previsto na Constituição Federal, na LDBEN e demais instrumentos legais. Máxime que tratamos no texto da igualdade material, essa realmente, muito distanciada da relação entre o estado e a cidadania.
\end{abstract}

Palavras chave: educação, ética, estado brasileiro.

\section{REFLEXIONES SOBRE ÉTICA, ESTADO BRASILEÑO Y EDUCACIÓN}

\section{RESUMEN}

En este artículo, discutimos la cuestión ética en las relaciones entre el estado brasileño y la ciudadanía desde de el análisis del papel del Estado, principalmente, en la esfera educativa. Para ello desarrollamos una revisión bibliográfica y, asimismo, hemos recurrido a nuestra propia experiencia y conocimiento teórico-práctico como profesional de la educación. Inicialmente, hicimos un rescate del sentido de la ética y a continuación realizamos el análisis al cual nos hemos propuesto adoptando como referencia el valor igualdad entre los individuos en lo que concierne al acceso a la educación. La investigación nos ha permitido concluir que la relación entre el estado brasileño y sus ciudadanos carece de ética, puesto que la igualdad siquiera es alcanzada desde el punto de vista formal conforme previsto en la Constitución del país, en la Ley de Directrices y Bases de la Educación Nacional LDBEN - y demás dispositivos legales. Máxime que tratamos en el texto de la igualdad material, esa efectivamente muy alejada de la relación entre el Estado y la ciudadanía.

Palabras clave: educación, ética, estado brasileño. 


\title{
REFLEXÕES SOBRE ÉTICA, ESTADO BRASILEIRO E EDUCAÇÃO
}

\begin{abstract}
Mulheres e homens, seres histórico-sociais, nos tornamos capazes de comparar, de valorar, de intervir, de escolher, de decidir, de romper, por tudo isso nos fazemos seres éticos [...]. Não é possível pensar os seres humanos longe, sequer, da ética, quanto mais fora dela. Estar longe, ou pior, fora da ética, entre nós, mulheres e homens, é uma transgressão (FREIRE, 1996, p.33)
\end{abstract}

\section{INTRODUÇÃO}

Neste trabalho, nos propomos a discutir a questão ética nas relações entre o Estado brasileiro e os cidadãos, a partir de uma análise do papel do Estado, especialmente na esfera educacional. Para isso nos valemos de uma revisão bibliográfica e de nossa própria experiência e conhecimento como profissional da educação.

É importante esclarecer que o trabalho não tem caráter de análise exaustiva sobre a matéria em questão. Na verdade, objetivamos contribuir para o debate e o diálogo em torno desse importante tema, na perspectiva de buscar caminhos que possam alicerçar uma política de Estado para a educação nacional comprometida com uma sociedade justa.

\section{RESGATANDO O SENTIDO DA ÉTICA}

Desde o ponto de vista da teoria, a importância da ética está em sua capacidade de explicar a realidade com vistas a iluminá-la, definindo, portanto, alguns traços essenciais ou a própria essência do comportamento moral. Assim sendo, há um vínculo inexorável entre ética, comportamento moral e responsabilidade, o que nos remete a outra importante questão, a vontade de agir de uma ou de outra forma.

Entretanto, é importante ter clara a diferença fundamental entre a ética e outras formas de comportamento humano como a política, a religião, o direito, o trato social, a moral, entre outros, os quais se baseiam em recomendações ou prescrições (COSTA, B.; PUCCI, B., 2001). Dessa forma, decidir e atuar em uma situação específica e concreta é um problema prático-moral, já a ética tem como espaço de atuação a investigação acerca de como a responsabilidade moral se relaciona com a liberdade e com o determinismo ao qual estão sujeitas as nossas ações. E isso é um problema teórico, cujo âmbito de estudo está no campo da ética. Em síntese, com relação ao bem, por exemplo, a ética tem por objeto estudar o que é o bem e por que ele é um valor fundamental para a sociedade, mas não prescreve situações em que se deve fazer o bem, enquanto a moral prescreve situações concretas, define normas de conduta.

Nessa perspectiva, nos propomos a investigar que tipo de relação entre o estado e os cidadãos pode ser considerada ética no campo educacional.

Partimos da consideração de que a ética está relacionada com um conjunto de valores sociais, políticos, econômicos e culturais nos quais se fundamentam determinada sociedade. Assim, numa sociedade para a qual o valor igualdade é fundamental e, portanto, irrenunciável, essa relação entre os cidadãos e o estado é ética quando os primeiros, independentemente, de sua origem socioeconômica, gênero, etnia, conviç̧ão religiosa ou 
política, entre outros aspectos que os diferenciam entre si, têm acesso a um sistema educacional público, gratuito, de qualidade, universal e unitário, porque, dessa forma, se estará potencializando a igualdade entre os cidadãos.

Isso não significa que em qualquer sociedade seja fundamental eticamente que a relação entre o estado e seus cidadãos seja baseada, obrigatoriamente, nesse valor - a igualdade. Isso porque pelo princípio da autodeterminação dos povos, cada povo tem liberdade para definir que sociedade deseja construir para si próprio.

Evidentemente, a liberdade proveniente dessa autodeterminação não pode afetar a liberdade e autodeterminação de outros povos, exatamente porque a condição básica para que uma ação/relação seja considerada ética é que essa seja orientada pelo sentido de fazer/proporcionar o bem, a vida justa, a felicidade.

Dessa forma, são múltiplas as possibilidades de relações entre o estado e a cidadania serem ou não éticas, dependendo do conjunto de valores em que se sustenta cada sociedade.

Passemos agora a desenvolver algumas reflexões sobre a relação entre o estado brasileiro e a educação proporcionada aos cidadãos, adotando a igualdade como valor de referência.

\section{O ACESSO À EDUCAÇÃO NO ESTADO BRASILEIRO}

Não podemos discutir o acesso à educação sem antes refletir, ainda que não exaustivamente, sobre o modelo de desenvolvimento socioeconômico do país com o objetivo de lançar um olhar mais amplo sobre a sociedade brasileira. Uma mirada que nos permita enxergar as partes, o todo e as inter-relações existentes.

Já afirmamos em outros textos (MOURA, 2004a, 2004b e 2005) que o modelo de desenvolvimento socioeconômico vigente no Brasil, produto da dependência econômica externa histórica do país ${ }^{1}$, é baseado nas exportações agroindustrial, agropecuária e de matérias primas e na importação acrítica das tecnologias produzidas nos países de capitalismo avançado. Isso, ao longo do tempo, vem fazendo com que o país não tenha um modelo próprio de desenvolvimento orientado às suas necessidades econômicas e melhorias sociais. Ao invés disso, historicamente, prevalece a submissão aos indicadores econômicos ditados desde fora, aos organismos internacionais de financiamento e aos investidores internacionais, principalmente os de curto prazo - na verdade, especuladores.

Diante da ausência desse modelo de desenvolvimento socioeconômico próprio, não há políticas de estado para os diversos segmentos que constituem a sociedade brasileira. Assim, não há políticas de estado para a saúde, para a educação, para a segurança, para a habitação, entre outras, voltadas para promoção da igualdade entre os cidadãos, políticas que contribuiriam para a construção de uma configuração própria e diferente da atual para o estado brasileiro.

Diante desse contexto e com a consolidação do modelo de sociedade neoliberal, apoiada na globalização dos mercados (ANDERSON, 1996), a qual, por sua vez, é viabilizada e potencializada pelos avanços tecnológicos, principalmente, pelas chamadas tecnologias da

\footnotetext{
${ }^{1}$ Como este não é o tema central deste artigo, sugiro ver alguns trabalhos que tratam essa questão de forma profunda: FREITAG (1979); FURTADO (1992); DIETERICH (1999), só para citar alguns exemplos.
} 
informação e da comunicação - TIC, essa situação se agrava a passos mais largos, de modo que a distância entre os incluídos e os excluídos aumenta cada vez mais.

Infelizmente, esse cenário é coerente com a lógica do mercado global. Esses coletivos excluídos constituem a "população precária” (DIETERICH, 1999; MOURA, 2004a). Esta população tem um papel relevante ao constituir-se em um exército de reserva e contribuir para exercer uma constante pressão de baixa sobre os salários dos que têm emprego e funcionar como armazém humano para equilibrar as oscilações conjunturais da demanda de "mão de obra".

Apesar dessa dura realidade, existe outro tipo de sociedade que pode ser buscada. Uma sociedade que tenha o ser humano e suas relações com o meio-ambiente e a natureza em geral como centro e na qual a tecnologia esteja submetida a uma racionalidade ética no lugar de estar a serviço exclusivo do mercado e do fortalecimento dos indicadores econômicos. Nessa sociedade, a construção do conhecimento deve estar voltada para a busca de soluções aos problemas das pessoas e das comunidades menos favorecidas na perspectiva da edificação de uma sociedade socialmente justa.

Nesta sociedade, o homem deve ser concebido como um ser integral, "o qual, no confronto com outros sujeitos, afirma a sua identidade social e política e reconhece a identidade de seus semelhantes, ambas construídas nos processos de desenvolvimento da individualização e da intersubjetividade” (CEFET-RN, 1999, p. 47). Essa concepção de homem resulta em pensar um "eu” socialmente competente, um sujeito político, um cidadão capaz de atuar sobre a realidade e, dessa forma, ter participação ativa na história da sociedade da qual faz parte e na construção de sua própria história.

Esta concepção de homem é mais ampla do que a requerida pela lógica neoliberal, de forma que os processos educativos estruturados a partir desse referencial deverão contribuir para a formação de cidadãos capazes de participar politicamente na sociedade, atuando como sujeitos nas esferas pública, privada e no terceiro setor, espaços privilegiados da prática cidadã, em função de transformações que apontem na direção dessa sociedade justa e igualitária.

Entretanto, a opção por esse modelo alternativo de desenvolvimento socioeconômico não ocorreu no Brasil. A falta dessa opção, além das implicações já mencionadas, também contribui para outro fator limitante na busca da construção de uma política de estado para a educação do país: a fragmentação das discussões dos grandes temas da agenda educacional brasileira. Nesse contexto, atualmente está-se discutindo de forma separada a Reforma da Educação Superior ${ }^{2}$, um Anteprojeto de Lei Orgânica da Educação Profissional e Tecnológica ${ }^{3}$, além da revisão dos Parâmetros Curriculares para a Educação Básica. Na

\footnotetext{
${ }^{2}$ O Anteprojeto de Lei de Reforma da Educação Superior, atualmente na iminência de ser encaminhado ao Congresso Nacional, prevê a revogação de praticamente todos os artigos da LDBEN que tratam da Educação Superior.

3 As discussões relativas à Lei Orgânica da Educação Profissional e Tecnológica - EPT - foram intensas durante o ano de 2004, tendo ocorrido, inclusive, três seminários regionais realizados entre outubro e dezembro. Esses seminários, promovidos pela SETEC/MEC, envolveram vários coletivos vinculados à EPT como também muitos recursos com suas diárias e passagens. Apesar disso, em 2005 a Reforma da Educação Superior - que vem ocupando maiores espaços na agenda do MEC - e a alternância entre as pessoas que ocupam cargos relacionados com essa atividade no âmbito da SETEC, provocaram a descontinuidade das ações. Entretanto, é bastante provável que a Educação Profissional, brevemente, volte a ser discutida na forma de Lei Orgânica ou sob outra denominação.
} 
verdade, a mudança mais ampla e que incorporaria todas as ações parciais seria a da própria Lei de Diretrizes e Bases da Educação Nacional - LDBEN, cujo caráter minimalista está viabilizando o aprofundamento do processo de mercantilização da educação (FRIGOTTO, 2001).

Contudo, a atual correlação de forças políticas instaladas no centro do poder político do país não nos fornece indicadores de que um amplo processo de (re)discussão da LDBEN nos conduziria a uma Lei comprometida com a educação pública e, em conseqüência, com a busca de uma sociedade socialmente justa. Essa discussão teria que enfrentar a questão da educação pública versus educação privada, em todos os níveis, na perspectiva da opção pelo fortalecimento da educação pública, gratuita e de qualidade. Infelizmente, reafirmamos, o cenário político configurado pela atual correlação de forças não nos permite ser ingênuos a ponto de pensar que a reabertura dessa discussão nos levaria à direção almejada por aqueles que buscam uma sociedade cujo modelo de desenvolvimento socioeconômico não seja ditado, quase exclusivamente, pelos interesses do mercado.

Dessa forma, tanto o acesso à educação no Brasil como o tipo de educação ao qual se tem acesso depende fundamentalmente da origem socioeconômica de cada indivíduo.

Nesse contexto, nos últimos anos, houve na educação básica um grande aumento quantitativo da oferta pública. Dados do Censo Escolar de 2004 revelam que quase 97\% das crianças de 7 a 14 anos estão na escola, entretanto, essa ampliação não veio acompanhada de melhoria qualitativa, precisamente pela falta de investimentos decorrentes da ausência de uma política de estado para esse fim.

Assim, para os filhos das classes média-alta e alta, oferece-se uma educação de caráter mais "refinado" e, portanto, voltada para as ciências e as artes, quase sempre em escolas privadas de alto custo mensal, inacessíveis aos filhos da classe trabalhadora.

Cabe ressaltar ainda que não há linearidade entre as escolas privadas, pois existem as de "primeira marca" para aquelas famílias de "renda de primeira”, as de "segunda” para as famílias de "renda de segunda" e, assim sucessivamente, até o limite inferior do rendimento das famílias, abaixo do qual não é mais viável que o mercado educativo ofereça algum "produto" por não haver possibilidade de retorno seguro (lucratividade). A partir desse limite, os filhos dessas famílias (a classe operária brasileira) vão para a escola pública.

Não podemos deixar de destacar que a educação proporcionada em grande parte da rede privada, mesmo em algumas daquelas escolas de “primeira linha”, padece de um problema crucial. Acontece que, ao funcionarem desde a lógica de mercado, estão focadas na "satisfação do cliente", o que, nesse caso específico, geralmente se manifesta pela aprovação no vestibular. Desse modo, as escolas, principalmente no ensino médio, estruturam seus currículos de forma a conseguir que o maior número possível de estudantes seja aprovado nos vestibulares das instituições de educação superior que gozem de melhor reconhecimento perante a sociedade, paradoxalmente, as boas universidades públicas e gratuitas.

Esse tipo de oferta educacional prejudica intensamente a formação do estudante, já que esse passa a resumir sua expectativa de vida na aprovação no vestibular e não avança na 
perspectiva de sua formação integral ${ }^{4}$. Isso caracteriza uma verdadeira inversão de prioridades educacionais.

Evidentemente, a formação deveria ser integral e igualitária, sendo norteada pela prática social, que o estudante vivencia enquanto se forma, e pela preparação para a vida, o que supõe uma sólida formação científica, humanística e tecnológica o que lhes permitiria uma preparação efetiva para a participação política, social, cultural, econômica e no mundo do trabalho, o que também inclui a continuidade de estudos, mas não a tem como um fim em si mesmo.

No entanto, a formação proporcionada por parcelas significativas dessas escolas privadas substitui o todo (a formação integral) pela parte (ingresso em um curso superior), ou dito de outra forma, assume a meta obsessiva de aprovar seus alunos no vestibular em função da necessidade imperiosa do mercado e da "qualidade total" de satisfazer as necessidades dos clientes - os próprios alunos e suas famílias.

Por outro lado, os filhos da classe operária, em geral, vão para a educação pública. Apesar de existirem excelentes escolas públicas espalhadas ao longo da geografia do país, infelizmente, essa não é a regra. Desafortunadamente, as condições materiais concretas da maioria das escolas públicas brasileiras não lhes permite oferecer uma educação de qualidade para os que a ela têm acesso. E o problema não está exatamente na escola. Está no seu financiamento deficitário, nos baixos salários dos professores como também na própria falta de professores em termos quantitativos e, muitas, na deficiente formação dos que nela estão, entre tantos outros problemas. Assim sendo, essa escola pública, embora tente reproduzir o modelo das privadas, em geral, não consegue oferecer essa educação “científica”, impedindo, na prática, que seus egressos continuem os estudos na educação superior. Dessa forma, resta a esses jovens, quando muito, a formação profissional de caráter meramente instrumental para um posto de trabalho em uma escola patronal ou privada, não poucas vezes, de qualidade duvidosa, inclusive, para os limites restritos aos quais se propõem.

Outra possibilidade desses coletivos é a tentava de ingresso em um Centro Federal de Educação Tecnológica - CEFET, Escola Técnica Federal - ETF, Escola Agrotécnica Federal - $\mathrm{EAF}^{5}$, instituições que historicamente atuam com referência em vários elementos que constituem a formação integral, entretanto, isso não é fácil, já que são organizações cuja concorrência para ingresso é muito elevada, uma vez que a quantidade de vagas que podem ofertar é muito menor do que a demanda. Para ilustrar melhor essa afirmação, apresentamos a distribuição das matrículas no Ensino Médio e na EP técnica de nível médio brasileira, em 2004.

\footnotetext{
${ }^{4}$ A finalidade da formação integral é a superação da dualidade histórica presente na educação brasileira entre teoria e prática e cultura geral versus cultura técnica. Essa dualidade não é fruto do acaso, mas sim da separação entre a educação proporcionada aos filhos das classes média-alta e alta e aquela permitida aos filhos dos trabalhadores. Entretanto, como o objetivo central deste trabalho não está circunscrito a essa oferta educacional, sugerimos, para um maior aprofundamento sobre a matéria, consultar: Frigotto; Ciavatta; e Ramos, 2005; CEFET-RN, 2005; e Baracho e outros (3), 2005.

${ }^{5}$ É importante esclarecer que em alguns estados como em São Paulo a rede Paula Souza atua fortemente na educação tecnológica. Na mesma direção, o estado do Paraná também está ampliando de forma significativa a oferta de EP. Não obstante, essa não é a realidade brasileira.
} 
Tabela 1 - Matrícula no ensino médio e na educação profissional técnica de nível médio no Brasil por dependência administrativa

\begin{tabular}{|c|c|c|c|c|c|}
\hline \multirow{2}{*}{$\begin{array}{l}\text { Dependência } \\
\text { administrativa }\end{array}$} & \multirow{2}{*}{$\begin{array}{c}\text { Ensino } \\
\text { Médio } \\
\text { (Regular) }\end{array}$} & \multicolumn{2}{|c|}{ Ensino Médio } & \multirow{2}{*}{$\begin{array}{l}\text { Ensino Médio } \\
\text { (TOTAL) }\end{array}$} & \multirow{2}{*}{$\begin{array}{c}\text { Educação } \\
\text { Profissional - } \\
\text { Nível técnico }\end{array}$} \\
\hline & & Presencial & $\begin{array}{c}\text { Semi- } \\
\text { presencial }\end{array}$ & & \\
\hline Brasil & 9.169 .357 & 1.157 .593 & 551.460 & 10.878 .410 & 676.093 \\
\hline Federal & 67.652 & 316 & 0 & 67.968 & 82.293 \\
\hline Estadual & 7.800 .983 & 950.536 & 497.306 & 9.248 .825 & 179.456 \\
\hline Municipal & 189.331 & 37.894 & 17.993 & 245.218 & 21.642 \\
\hline Privada & 1.111 .391 & 168.847 & 36.161 & 1.316 .399 & 392.702 \\
\hline
\end{tabular}

Fonte: elaboração nossa, a partir do Censo Escolar 2004.

Ao analisar a Tabela 1, percebemos que a oferta de cursos técnicos de nível médio corresponde a apenas a 6,21\% da oferta total do Ensino Médio. Além disso, a oferta no âmbito federal corresponde a parcos $21,7 \%$ do total de matrículas dos cursos técnicos de nível médio. E, ainda mais, a oferta de cursos técnicos de nível médio é maior no âmbito privado $(58,02 \%)$ do que no público (41,98\%), incluindo as esferas municipal, estadual e federal.

Como síntese da situação na educação básica, podemos dizer que existe uma estratificação muito acentuada, o que, além, dos aspectos já mencionados, acarreta em uma segmentação social sem precedentes. Isso ocorre porque os indivíduos que freqüentam determinada escola só conhecem a realidade daqueles que estudam em escolas do mesmo "padrão", permanecendo isolados dos outros estratos.

Cabe destacar que essa segmentação não ocorre apenas entre os que estudam em escolas públicas e os que freqüentam escolas privadas, já que, conforme mencionamos anteriormente, dentre as escolas privadas existe uma grande diversidade, viabilizada pela lógica da sociedade da prestação de serviços na qual os que têm maior poder de compra podem pagar por “melhores” escolas para seus filhos.

Esse contexto inviabiliza o contato, a troca de experiências e o conhecimento mútuo dos indivíduos provenientes de realidades socioeconômicas distintas. Essa mescla é imprescindível para que uns conheçam os outros, para que se tome consciência de que as pessoas e os grupos sociais são diferentes, mas que nem por isso uns são melhores ou piores que os demais.

Por outro lado, esse contato, essa aproximação é fundamental para que cada indivíduo tome consciência de que as necessidades e expectativas do outro podem ajudar a construir a seu próprio "eu”, a sua própria identidade e, inclusive, mudar a forma como o "eu" de cada um vê o mundo e os outros. Seguramente, essa interação contribuiria para uma maior compreensão entre os diversos segmentos, o que ajudaria no desenvolvimento de uma concepção compartilhada do que é ética, igualdade, solidariedade, entre outros aspectos relevantes que poderiam contribuir para a construção de uma identidade social e cultural da sociedade brasileira, enfim contribuiria para uma maior coesão social. E isso só é possível através de uma escola pública, gratuita, igualitária, laica e universal.

Para analisar a situação da Educação Superior, partimos do anteprojeto de lei que visa estabelecer a sua reforma para exemplificar um aspecto que ratifica o pensamento desenvolvido ao longo do texto. Ocorre que, na impossibilidade de atacar a raiz da questão - a igualdade no acesso à educação, o que implicaria em promover o fortalecimento e ampliação da educação superior pública, no Anteprojeto de Lei tenta-se definir uma função 
social para as instituições de educação superior privadas. Entretanto, os que estamos acompanhando este processo, já vimos as reações exacerbadas daqueles que representam as empresas comerciais que atuam na educação superior. Isso ocorre porque está aflorando a incompatibilidade entre os fins educacionais que efetivamente têm uma função social e os objetivos do mercado os quais, evidentemente, visam à acumulação do capital através da venda de cursos/diplomas à maioria da população que não tem acesso às instituições públicas de educação superior precisamente pela falta de uma política de estado para educação que tenha como referência a igualdade.

Enquanto isso, os dados oficiais ratificam que a oferta de educação superior no país é predominantemente privada e que isso vem aumentando ao longo dos últimos anos, conforme apresentado na Tabela 2.

Tabela 2 - Matrículas nos Cursos de Graduação no Brasil

\begin{tabular}{|c|c|c|c|}
\hline Ano & Total & Público \% & Privado \% \\
\hline 1994 & 1.661 .034 & $690.450(41,6)$ & $970.584(58,4)$ \\
\hline 1998 & 2.125 .958 & $804.729(37,9)$ & $1.321 .229(62,1)$ \\
\hline 2002 & 3.482 .069 & $1.053 .811(30,3)$ & $2.428 .258(69,7)$ \\
\hline 2003 & 3.887 .771 & $1.137 .119(29,2)$ & $2.750 .652(70,8)$ \\
\hline \multicolumn{3}{|c|}{ Fonte: INEP, 2004 }
\end{tabular}

Além disso, ao analisar e comparar as Tabelas 1 e 2, ainda verificamos que dos quase 11 milhões de estudantes matriculados no Ensino Médio, incluindo os da modalidade EJA, a absoluta maioria não chega à Educação Superior, onde 70,8 \% da matrícula encontram-se em instituições privadas.

Diante de todo o exposto e considerando o referencial adotado neste trabalho - o valor igualdade entre os indivíduos no que se refere ao acesso à educação -, podemos concluir que a relação entre o estado brasileiro e seus cidadãos carece de ética, uma vez que essa igualdade não é alcançada sequer do ponto de vista formal previsto na Constituição Federal, na LDBEN e demais instrumentos legais. Máxime que estamos tratando neste documento da igualdade material, essa realmente, muito distanciada da relação entre o estado e a cidadania.

A partir dessa conclusão é necessário refletir um pouco mais sobre a postura dos dois pólos envolvidos - o estado e os cidadãos. Iniciaremos essa reflexão a partir de Tiburi $(2001)^{6}$ ao interpretar o pensamento de Adorno no campo da ética e da moral. Segundo a autora a ética, a moral e a filosofia, na visão de Adorno, têm o papel de

\begin{abstract}
Acabar com o sofrimento que está no sujeito, mas que não pode ser eliminado por cada um em particular e sim pela espécie da qual ele depende. Um incremento no sujeito só adquire sentido em função do universal ao qual ele está atrelado, que o forma e que, na contrapartida, é formado por ele. A ação contra o sofrimento é, para Adorno, a atitude normal da espécie, que deveria solidarizarse consigo mesma e com tudo o que é vivo como única forma de agir contra o sofrimento. Por isso é necessária crítica ao individualismo no sentido de autoabsolutização do sujeito e ao coletivismo tão repressor quanto aquele, pois ambos, para Adorno, se completam na falsidade, impedindo a formação da solidariedade. (TIBURI, 2001, p. 100)
\end{abstract}

\footnotetext{
${ }^{6}$ Neste texto a autora discute o pensamento de Adorno em relação à ética.
} 
À luz dessa relação entre o individual e o coletivo acima apresentada, vamos discorrer sobre a relação entre o estado e os cidadãos, partindo da interrogação: quem define a forma de agir do estado? Ora, quem executa a ação do estado são as instituições que o representam. Mas, e quem decide a forma de atuar e as políticas que orientam essas instituições ${ }^{7}$ ? São os indivíduos que trabalham e dirigem as instituições do estado. Então, seria correto concluir que a ação do estado no campo educacional não é ética porque falta ética na ação daqueles que trabalham e dirigem as instituições do estado? Sim e não, a nosso ver. Sim porque isso é parte da explicação do problema. Mas também é não, porque a crise ética não atinge apenas os que trabalham e dirigem instituições que constituem o estado. Acontece que a crise ética e de valores é muito maior e abrange toda a sociedade, incluindo o estado, os indivíduos e as relações entre o público e o privado. Na verdade, a ética enquanto busca de uma vida justa para os que integram uma determinada sociedade vem sendo solapada ao longo da história, principalmente, a partir da consolidação do capitalismo como forma hegemônica de organização das sociedades, fato que espalhou a ideologia do individualismo e do privado em detrimento da coletividade, do público e da solidariedade, conforme nos explica Carone (2001, p.125-126):

Inicialmente, a ética era um objeto privilegiado da filosofia - Sócrates, Platão e Aristóteles se perguntavam, então, sobre o que era a ética no domínio da política ou dos negócios públicos dos cidadãos da polis ateniense. A partir do século XVII, a ética foi drasticamente restringida aos assuntos da conduta individual, às questões de foro interno das pessoas, ou seja, à esfera privada. No entanto, a esfera privada foi sendo paulatinamente destituída de qualquer autonomia em face do desenvolvimento do próprio capitalismo.

Dessa forma, os problemas éticos permeiam toda a sociedade e não apenas o estado e os indivíduos que atuam e dirigem as instituições que o representam.

Assim, se produz uma espiral negativa no campo da ética, ou seja, o estado não age de forma ética em relação aos cidadãos, esses, por sua vez, (re)agem orientados pela ausência da ética, de modo que o modelo se retro-alimenta de forma recursiva, ou seja, há um reforço mútuo da ação do estado e dos cidadãos gerando ciclos que a cada vez deterioram ainda mais essas relações.

Vamos colocar um exemplo prático com o intuito de esclarecer melhor essa linha de pensamento: o estado, através de suas instituições, submete os cidadãos a impostos abusivos sob alegação da necessidade de promover a "justa" redistribuição da riqueza, mas, na verdade, não usa a arrecadação correspondente para promover a redistribuição anunciada ${ }^{8}$. Em vista disso, grande parte da cidadania sente-se "autorizada” a praticar a "justiça” e não pagar os impostos estabelecidos pelas instituições do estado, já que esse

\footnotetext{
${ }^{7}$ É preciso levar em consideração que nos países periféricos submetidos ao neoliberalismo - caso do Brasil -, o poder do estado nacional está muito reduzido. O Estado não tem controle nem influencia nas decisões sobre os fluxos de capital de uma nação a outra ou de um setor econômico a outro. Nesse contexto, o estado nacional se debilita; prevalecem as políticas liberais de desregulamentação da economia; diminuem os investimentos nos setores sociais como educação, saúde e segurança públicas, entre outros; são privatizadas as empresas públicas sob o argumento de que a iniciativa privada faz melhor e mais rápido, sem preocupação com os valores e interesses que movem essas empresas e que benefícios sociais estão resultando dessas mudanças. De qualquer maneira, também não se pode deixar de considerar que os indivíduos que trabalham e, principalmente, os que dirigem as instituições do Estado podem contribuir ou não para que essa situação permaneça inalterada ou seja transformada.
}

\footnotetext{
${ }^{8}$ A situação, muitas vezes, ainda é mais grave porque o capital tem muitos mecanismos de proteção de maneira que, em geral, o capital paga menos impostos do que trabalho assalariado.
} 
não está sendo ético em sua aplicação. Ocorre que a sonegação é tão antiética quanto a ação do estado e das instituições que o representam, as quais, por sua vez, são dirigidas por cidadãos. O ciclo negativo ao qual nos referimos anteriormente, nesse caso, pode ser caracterizado da seguinte maneira: o estado cobra maiores impostos porque a sonegação é muito elevada, enquanto os cidadãos e as empresas sonegam porque os impostos são muito altos, fatos que se reforçam mutuamente. Não percamos de vista que essa lógica repete-se em muitas outras situações.

Esse raciocínio reforça o pensamento desenvolvido ao longo do trabalho que aponta para a imperiosa necessidade de romper esses ciclos negativos. Nessa esfera, ratificamos que a educação igualitária para toda a população independentemente da origem socioeconômica de seus destinatários possa contribuir para esse rompimento. Isso é fundamental para afrontar a crise de valores e de ética da sociedade, pois se todos os cidadãos, de qualquer origem, tiverem acesso ao mesmo tipo de educação será possível pensar na construção de um conjunto de valores a serem assumidos e compartilhados pela sociedade brasileira e, em conseqüência, um significado comum para a ética e uma identidade para a população, baseada em nossos próprios valores e cultura. Evidentemente, a escola não é o único espaço de prática social que vai contribuir para a construção desse sentido da ética e de identidade coletiva, mas é uma possibilidade concreta e privilegiada, pois se espera que todos os cidadãos tenham acesso a esse espaço.

Ao chegar a essas conclusões, nos sentimos desafiados a refletir sobre que tipo educação deveria o estado brasileiro empenhar-se para oferecê-la à população, que tipo de relação entre esse estado nacional e seus cidadãos poderia ser considerada ética a partir do referencial adotado neste trabalho - o valor igualdade entre os cidadãos no acesso à educação.

\section{EM BUSCA DE UMA ÉTICA NO CAMPO EDUCACIONAL PARA A RELAÇÃO ENTRE O ESTADO BRASILEIRO E A CIDADANIA}

Um sistema educacional público, gratuito, de qualidade, universal, laico e unitário é o pressuposto para que, a partir do referencial adotado neste trabalho, a relação entre o estado e os cidadãos possa ser ética, pois dessa forma se estará potencializando a igualdade material entre os cidadãos.

No Quadro 1, apresentamos uma representação gráfica na qual resumimos aspectos importantes dessas relações. Nesse Quadro 1 evidenciamos que o estado, através das políticas educacionais, das instituições de educação e de seus profissionais, tem a responsabilidade de oferecer educação de qualidade à população, independentemente da origem socioeconômica dos indivíduos.

A educação de qualidade aqui deve ser entendida como uma ação voltada para a formação integral do cidadão em todos os níveis, ciclos e etapas, tanto na educação básica quanto na superior. Para que essa formação seja efetivamente integral e ética, ela precisa ser orientada pelo respeito constante aos educandos, de modo que não pode em momento algum ser confundida com treinamento, pois "transformar a experiência educativa em puro treinamento técnico é amesquinhar o que há de fundamentalmente humano no exercício educativo: o seu caráter formador (FREIRE, 1996, p.33)”. 
Quadro 1 - Relações entre ética, estado e educação, a partir da igualdade como valor de referência.

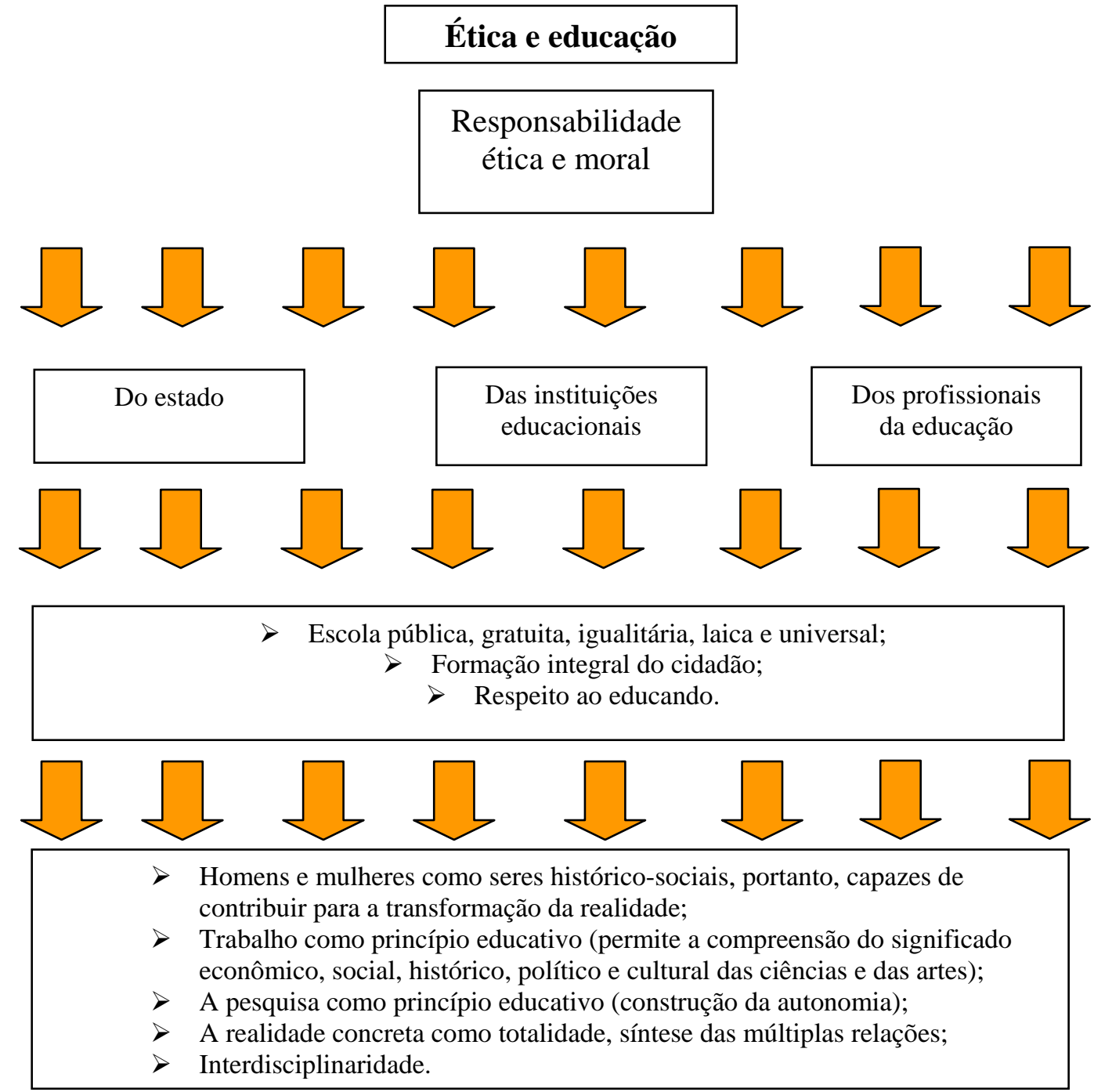

Ainda nos falta tecer alguns comentários acerca dos princípios nos quais devem se basear a educação pela qual advogamos neste texto (Quadro 1). Um deles é a necessidade de assumir a compreensão do homem como um ser histórico-social e crítico, portanto, capaz de transformar a realidade, ou seja, um ser que

[...] busca a autonomia, a auto-realização e a emancipação através de sua participação responsável e crítica nas esferas sócio-econômico-políticas. Isto consiste em perceber o homem como um ser capaz de colocar-se diante da realidade histórica para, entre outros aspectos, reagir à coerção da sociedade, questionar as pretensões de validade e de normas sociais, construir uma unidade de interesses e descobrir novas estratégias de atuação solidária (CEFET-RN, 1999:47).

Outro princípio fundamental é a assunção do trabalho como princípio educativo o que permite a compreensão do significado econômico, social, histórico, político e cultural das ciências e das Artes. Assim sendo, ter o trabalho como princípio educativo não significa apenas tê-lo como uma técnica de ensino-aprendizagem, mas como um princípio ético e político (FRIGOTTO, 2005). Nessa perspectiva, o trabalho é 
[...] ao mesmo tempo, um dever e um direito. Um dever por ser justo que todos colaborem na produção dos bens materiais, culturais e simbólicos, fundamentais à produção da vida humana. Um direito pelo fato de o ser humano se constituir em um ser da natureza que necessita estabelecer, por sua ação consciente, um metabolismo com o meio natural, transformando em bens, para a sua produção e reprodução. (FRIGOTTO, 2005, p. 61)

A pesquisa como princípio educativo é outro pressuposto básico, pois contribui para a construção da autonomia intelectual do educando. Portanto, a pesquisa deve ser intrínseca ao ensino e estar orientada ao estudo e à busca de soluções para as questões práticas do dia-a-dia do meio em que vive o estudante, ou seja, sua família, sua rua, seu bairro, sua cidade, a própria escola, as empresas, as associações comunitárias ou outras organizações da sociedade que constituem o entorno do educando e da instituição.

Nesse sentido, assumimos que a pesquisa, enquanto princípio educativo (DEMO, 2000), deve estar presente em todas as ofertas, independentemente, do nível educacional e da faixa etária dos alunos, pois se localiza, de forma precípua, no campo das atitudes e dos valores. Evidentemente, a forma de abordagem deverá ser adequada a cada nível educacional, através de estratégias, métodos e objetivos próprios de cada oferta e do amadurecimento intelectual de cada grupo de estudantes.

No que se refere às atitudes, a pesquisa deve provocar a curiosidade do estudante em direção ao mundo que o cerca, deve gerar inquietude para que ele não incorpore "pacotes fechados" de visão de mundo, de informações e de saberes, quer sejam eles do senso comum (saber cotidiano), escolares ou científicos, mas que, ao invés disso, esteja sempre motivado para buscar a construção, a reconstrução e a desconstrução desses saberes e das relações sociais. Essas atitudes, quando despertadas ainda na educação básica, contribuem para que nas faixas etárias e níveis educacionais mais avançados o estudante possa formular questões de investigação no campo mais formal, quer seja na sua forma aplicada ou na denominada pesquisa de base ou acadêmica.

Na esfera dos valores, assumimos que a pesquisa aplicada e o desenvolvimento tecnológico devem estar voltados para a produção de bens e serviços que tenham a capacidade de melhorar as condições de vida dos coletivos sociais e não apenas de produzir bens de consumo para fortalecer o mercado e, em conseqüência, privilegiarem o valor de troca em detrimento do valor de uso, concentrando riqueza e aumentando o fosso entre os incluídos e os excluídos (MOURA, 2004a). Ao contrário, é, precisamente, o valor de uso que deve ser prioritário, pois é aí que se encontra a capacidade de estender os benefícios da geração dos conhecimentos e de produtos à sociedade em geral e, particularmente, aos coletivos que integram as camadas mais desfavorecidas desde o ponto de vista socioeconômico. É dessa forma que se pode submeter a racionalidade tecnológica à racionalidade ética.

Evidentemente, a pesquisa também pode e deve estar orientada a aspectos mais acadêmicos das ciências da natureza, sociais ou aplicadas, mas sempre tendo em consideração a que interesses correspondem e a quem pode beneficiar os possíveis resultados alcançados. Além disso, é bem mais fácil evoluir nessa perspectiva quando a atitude investigadora já foi mobilizada anteriormente, conforme destacado nos parágrafos anteriores. 
Diante do exposto, a unidade ensino/pesquisa colabora para edificar a autonomia dos indivíduos porque é através do desenvolvimento da capacidade de analisar criticamente o meio onde está inserido, orientado pela necessidade de transformá-lo e potencializada pela investigação, pela inquietude e pela responsabilidade social que o estudante, na perspectiva de Paulo Freire, deixa de ser um "depósito" de conhecimentos produzidos por uns (especialistas) e transmitidos por outros (geralmente os professores) e passa a construir, desconstruir e reconstruir suas próprias convicções a respeito da ciência, da tecnologia, do mundo e da própria vida.

Outro princípio básico é a compreensão de que a realidade concreta é uma totalidade, síntese das múltiplas relações (RAMOS, 2005). Isso significa que a realidade é um todo dialético e estruturado, produzido por um conjunto de fatos que se inter-relacionam e que podem ser compreendidos, mas não predeterminados ou previstos. Nesse sentido, os processos educacionais devem preocupar-se e ocupar-se de possibilitar que os estudantes desenvolvam a capacidade de compreender o conhecimento globalmente.

Mais um princípio fundamental da educação é a interdisciplinaridade, a qual não é entendida como uma justaposição de conhecimentos de diferentes componentes curriculares, mas sim, como uma atitude no desenvolvimento da ação pedagógica ou da abordagem aplicativa das ciências, implicando em estabelecer articulações e interações que sejam pertinentes e adequadas à construção do conhecimento de cada uma das disciplinas particulares envolvidas no processo ensino-aprendizagem.

Assim, a interdisciplinaridade repousa sobre uma atitude aberta, de respeito mútuo e de humildade. Para desenvolver uma postura verdadeiramente interdisciplinar é necessário assumir, a priori, os não saberes e as limitações individuais na disciplina da própria especialidade, mas também nas outras disciplinas objeto da ação interdisciplinar que se pretende realizar, evitando, assim, qualquer arrogância ou prepotência. Portanto, a interdisciplinaridade não pode ser entendida como a fusão de conteúdos ou de metodologias, mas, sim, como interface de conhecimentos parciais específicos que têm, por objetivo, um conhecer mais global.

Dessa forma, a interdisciplinaridade não supõe o fim das disciplinas, mas a articulação e o reforço mútuo entre elas em prol de um processo de construção do conhecimento mais global. Do mesmo modo, esse princípio interage fortemente com o princípio da compreensão de que a realidade concreta é uma totalidade e síntese das múltiplas relações entre as partes, de modo que os dois se fortalecem mutuamente.

\section{CONSIDERAÇÕES FINAIS}

Conforme já analisamos anteriormente, levar à prática uma política de estado para a educação brasileira que resulte em um modelo educacional conforme descrito no Quadro 1 não é tarefa simples, mas tem que ser a utopia a ser perseguida pelos que acreditam no ser humano como agente e sujeito de sua própria existência.

Nesse sentido, a utopia não pode ser concebida como algo inatingível, inalcançável, mas como um sonho, um projeto, uma idealização, a qual só poderá ser alcançada a partir da consciência e da esperança críticas, como nos ensina Paulo Freire (2000, p. 10) ao falar da esperança:

Não sou esperançoso por pura teimosia mas por imperativo existencial e histórico. Não quero dizer, porém, que, porque, esperançoso, atribuo à minha 
esperança o poder de transformar a realidade e, assim convencido, parto para o embate sem levar em consideração os dados concretos, materiais, afirmando que minha esperança basta. Minha esperança é necessária mas não é suficiente. Ela só, não ganha a luta, mas sem ela a luta fraqueja e titubeia. Precisamos de esperança crítica, como o peixe necessita da água despoluída.

Das palavras de Freire podemos apreender que ter esperança é muito diferente de atribuir a outrem a responsabilidade por uma situação presente ou de alguma mudança futura dessa mesma situação e esperar que essa força exterior resolva a situação. A esperança crítica está vinculada à necessidade ontológica do ser humano de ser crítico da realidade na qual está inserido, pois é a partir dessa consciência crítica que se pode avançar na perspectiva da transformação da realidade vigente.

\section{REFERÊNCIAS}

ANDERSON, P. Balanço do neoliberalismo. In: SADER, E.; GENTILI, P. (Orgs.). Pósneoliberalismo. As políticas sociais e o estado democrático. 3 ed.. Rio de Janeiro: Paz e Terra, 1996, p. 9-23.

CARONE, I A ética na prática da pesquisa científica. IN: LASTÓRIA, L.A.; COSTA, B.; PUCCI, B. (Orgs.) Teoria crítica, ética e educação. UNIMEP/Autores associados: Piracicaba/Campinas, 2001, p. 125-134.

CENTRO FEDERAL DE EDUCAÇÃO TECNOLÓGICA DO RIO GRANDE DO NORTE. Projeto de reestruturação curricular. Natal: CEFET-RN,1999.

Projeto político-pedagógico do CEFET-RN: um documento em construção. Disponível em http://www.cefetrn.br/ensino/projeto_pedagogico/Projeto_Pedagogico.pdf. Acesso 04.11.2005.

COSTA, B.; PUCCI, B. Teoria crítica, ética e educação. UNIMEP/Autores associados: Piracicaba/Campinas, 2001.

DEMO, P. Educar pela pesquisa. 4 ed.. Campinas: Autores Associados, 2000.

DIETERICH, H. Globalización, educación y democracia. 4 ed.. IN: La Aldea global. Tafalla: Txalaparta, 1999.

DOLLFUS, O. La mundialización. Barcelona: Edicions Bellaterra, 1999.

FREIRE, P. Pedagogia da autonomia. São Paulo: Paz e Terra, 1996.

FREIRE, P. Pedagogia da esperança. Um reencontro com a pedagogia do oprimido. São Paulo: UNESP, 2000.

FREITAG, B. Política educacional: uma retrospectiva histórica. In: Escola, estado e sociedade. 3 ed.. São Paulo: Cortez \& Moraes, 1979, p. 43-69.

FRIGOTTO, G. Mudanças societárias e as questões educacionais da atualidade no Brasil. Arquivo eletrônico (disquete), 2001. 
- Concepções e mudanças no mundo do trabalho e o ensino médio. IN: FRIGOTTO, G.; CIAVATTA, M.; e RAMOS, M. N. (Orgs.) Ensino médio integrado: concepção e contradições. São Paulo: Editora Cortez, 2005.

FRIGOTTO, G.; CIAVATTA, M.; e RAMOS, M. N. (Orgs.) Ensino médio integrado: concepção e contradições. São Paulo: Editora Cortez, 2005.

FURTADO, C. Brasil: a construção interrompida. São Paulo: Paz e Terra, 1998.

MOURA, D. Sociedade, educação, tecnologia e os usos das TIC nos processos educativos. In: Trabalhonecessário. Revista Eletrônica do neddate. Disponível em $<$ http://www.uff.br/trabalhonecessario/>. Acesso em 30/10/2004, 2004a.

. Formação e capacitação dos profissionais da educação profissional e tecnológica orientada a uma atuação socialmente produtiva. IN: III Seminário regional para discussão da proposta de Anteprojeto de Lei Orgânica para a EPT. Natal: disponível em $<$ http://mec.gov.br $>$. Acesso 12/12/2004, 2004b.

- Algumas implicações da reforma da educação superior sobre a educação profissional e tecnológica: continuação. Mimeo, 2005.

RAMOS, M. N. Possibilidades e desafios na organização do currículo integrado. IN: FRIGOTTO, G.; CIAVATTA, M.; e RAMOS, M. N. (Orgs.) Ensino médio integrado: concepção e contradições. São Paulo: Editora Cortez, 2005, p. 106-127.

SILVA e OUTROS (3) Alguns eixos norteadores para a construção do currículo dos cursos técnicos de nível médio articulados ao ensino médio na modalidade integrada. Mimeo, 2005.

TIBURI, M. Adorno e a impossibilidade da ética. IN: LASTÓRIA, L.A.; COSTA, B.; PUCCI, B. (Orgs.) Teoria crítica, ética e educação. UNIMEP/Autores Associados: Piracicaba/Campinas, 2001, p. 85-104. 